\title{
Original article (short paper) \\ Quality of life of Brazilian wheelchair tennis athletes across competitive and elite levels
}

\author{
Vitor Ciampolini \\ Universidade Federal de Santa Catarina, Florianópolis, SC, Brazil \\ Luis Columna \\ Syracuse University, Syracuse, United States of America \\ Bruno Lapolli \\ Tayná Iha \\ Universidade Federal de Santa Catarina, Florianópolis, SC, Brazil \\ Erika Carter Grosso \\ Syracuse University, Syracuse, United States of America \\ Diego Augusto Santos Silva \\ Universidade Federal de Santa Catarina, Florianópolis, SC, Brazil \\ Larissa Rafaela Galatti \\ Universidade Estadual de Campinas, Limeira, SP, Brazil
}

\begin{abstract}
Aims: This study aimed to identify Brazilian wheelchair tennis athletes' quality of life and to compare the perception scores between competitive and elite athletes. Methods: Participants were wheelchair tennis athletes $(\mathrm{N}=31)$ from Brazil (males $=25$, females $=6)$ divided into two groups: competitive and elite. Data was collected using the Brazilian version of the WHOQOL-Bref. The WHOQOL-Bref asks two general questions, and is thereafter divided into four main domains: 1) physical, psychological, social, and environment, which give us an understanding of their overall quality of life perception. Results: The results showed that overall, 29 out of the 31 athletes perceived their quality of life positively, regardless of the competitive level. However, statistically higher perceptions were found in the physical domain and the total score of quality of life of the elite group. Conclusion: The findings of this study suggest that even though participation in high-performance adapted sports may offer a stressful and exhausting environment, elite wheelchair tennis athletes from Brazil perceive themselves as having a better QoL than competitive athletes.
\end{abstract}

Keywords: adapted sports, people with disability, quality of life, elite athletes.

\section{Introduction}

Individuals with disabilities have often experienced inequities in various areas of life that negatively affected their overall physical and mental health, and consequently, their quality of life $(\mathrm{QoL})^{1,2}$. One of the areas where these inequities are present is sports. This is in part due to lack of facilities, community awareness, transportation, programs, as well as attitudinal barriers and architectural barriers to accessibility ${ }^{3,4}$.

The good news is that worldwide there is a push to promote people with disabilities' participation in adapted sports so they can acquire the multiple health, social, and psychological benefits that often result ${ }^{5-7}$. Also, because adapted sports practice integrates different types of disabilities and offers an enjoyable environment for social integration, it breaks down barriers of disability, prejudice, age, gender, and socioeconomic status ${ }^{8,9}$. Thus, adapted sports have been identified as an option for promoting an overall better QoL of athletes with disabilities ${ }^{9-13}$.
QoL refers to a multi-dimensional construct related to the person's perception and satisfaction of their own living conditions, considering all the different aspects of their own life ${ }^{10}$. In fact, there is no universal definition of QoL. Some professionals associate QoL with ideas of satisfaction and happiness, while for other professionals, QoL is more complex, including also general physical and mental health, cognitive functions, and private and social life functioning ${ }^{14}$.

Although researchers recommend participation of people with disabilities in adapted sports for rehabilitation and recreation purposes ${ }^{8,13}$, it seems that participation in sporting events do not receive the same attention. Sporting events create important opportunities for athletes to showcase their skills and integrate themselves into the community ${ }^{15,16}$. Events such as the Parapan and Paralympics games are widely respected and attended. Within the Parapan and the Paralympics games, wheelchair tennis has emerged as one of the favorites among players and spectators. Wheelchair tennis was invented in 1976 by Brad Parks and established as a Paralympic event at the 
Seoul 1988 Games $^{17}$. The levels of interest and competition have both been increasing.

Traditionally, highly competitive sporting events for athletes without disabilities have been identified as a source of stress due to physical, social, and emotional demands ${ }^{18-20}$. In addition, the literature regarding physical activity and physical education teaches us that families of children with disabilities tend to be overprotective, and in many cases do not provide physical activity opportunities for their family member with a disability because of fears of injury ${ }^{21,22}$. For these reasons, wheelchair tennis might not be desirable and supported by some families of athletes with disabilities.

On the one hand the literature regarding to the impact of adapted sports on people with physical disabilities QoL is well established, considering the multiple studies identifying positive perception of athletes with disabilities when compared to their inactive peers ${ }^{10-12}$. On the other hand, the literature regarding to the participation of athletes with disabilities in high-performance contexts is only incipient ${ }^{23}$, especially in terms of QoL perception. Hence, the purpose of this study was twofold: first, to identify Brazilian wheelchair tennis athletes' QoL in competitive settings; and second, to compare QoL perception scores between Brazilian competitive and elite wheelchair tennis athletes.

For purpose of this study, competitive athletes were defined as those players who practice sports for participating in regional, state and national competitions but neither reach the top results nor represent their country in international competitions. Elite athletes, on the other hand, were defined as top-level players who practice sports representing their country in national and international competitions, aiming to break records and to reach their maximum performance. We selected Brazil as a potential model for South America to advocate for an increase in adapted sports events in other South American countries. By promoting a better understanding of Brazilian wheelchair tennis athletes' QoL perceptions, other South American countries can follow suit and begin to launch similar programs within their own communities. Universities, parents of individuals with disabilities, and sport programs can use this information to integrate adapted sports into their programs.

\section{Methods}

\section{Participants}

Participants $(\mathrm{N}=31)$ consisted of wheelchair tennis athletes from Brazil $($ males $=25$, females $=6$ ) between the ages of 19-65 $(M=39.25, S D=11.5)$. The sample was stratified according to its competitive level: competitive group $(n=25)$ and elite group $(n=6)$. The competitive group was composed of athletes from a wheelchair tennis program run by a university in the south of Brazil, as well as participants of an international tournament of wheelchair tennis in the south of Brazil. The elite group was composed of the entire six members of the Brazilian wheelchair tennis national team, all of which have previously participated in Parapan American Games, and five out of the six subjects also participated in the London 2012 Paralympic Games. See table 1 for further information about the personal characteristics of both groups.

Table 1. Personal characteristics of Wheelchair tennis participants

\begin{tabular}{ccccccc}
\hline \multirow{2}{*}{ Competitive level } & Mean age (years) & \multicolumn{2}{c}{ Gender } & \multicolumn{2}{c}{ Cause of disability } & \multirow{2}{*}{ Average years practicing wheelchair tennis } \\
\cline { 3 - 6 } & & Female & Male & Congenital & Acquired & \\
\hline Competitive & $40.9 \pm 11.50$ & 4 & 21 & 2 & 23 & $7.2 \pm 6.22$ \\
\hline Elite & $32.8 \pm 10.25$ & 2 & 4 & 1 & 5 & $10.3 \pm 2.42$ \\
\hline Total & $39.2 \pm 11.57$ & 6 & 25 & 3 & 28 & $7.8 \pm 5.80$ \\
\hline
\end{tabular}

\section{Measuring Quality of Life}

The Brazilian version of the World Health Organization Quality of Life - Bref (WHOQOL-Bref) instrument was used to analyze the participants' quality of life perception. This instrument was validated and translated by Fleck, Louzada ${ }^{24}$ to Brazilian Portuguese and presented a satisfactory correlation $(0 \pm 69$ or above) to the English version. Fleck, Louzada ${ }^{24}$ found satisfactory reliability scores for all the domains: physical $(0.84)$, psychological (0.79), social (0.69), and environment (0.71). The WHOQOL-Bref uses a five-point Likert-scale design, where athletes rate their level of satisfaction (strongly agree, agree) or dissatisfaction (strongly disagree, disagree), or remain neutral by selecting 'neither agree nor disagree. The instrument contains 26 questions and is divided in four domains; see table 2 for further understanding. The authors also administered a short, informational survey to the athletes in order to collect personal information such as type of injury, cause of disability, competitive level, and total years practicing wheelchair tennis.

\section{Data Collection}

Prior to the selection of participants, permission was obtained from the lead author's university institutional review board. The research method was a descriptive, cross-sectional survey ${ }^{26}$. To 
participate in the study, subjects signed an informed consent (IC) given by two of the coauthors, who were trained and standardized for applying the IC, the instrument, and the informational survey. Participants spent 10 to 15 minutes completing the questionnaire.

Table 2. WHOQOL-Bref's facets according to the domains and the number of the question it appears

\begin{tabular}{|c|c|c|}
\hline Domain & Questions' facets & Question number in the WHOQOL-Bref \\
\hline \multirow{2}{*}{ General items } & Quality of life rating & 1 \\
\hline & Health satisfaction & 2 \\
\hline \multirow{7}{*}{ Physical } & Pain and discomfort & 3 \\
\hline & Medication & 4 \\
\hline & Energy and fatigue & 10 \\
\hline & Mobility & 15 \\
\hline & Sleep quality & 16 \\
\hline & Daily activities & 17 \\
\hline & Work capacity & 18 \\
\hline \multirow{6}{*}{ Psychological } & Positive Feelings & 5 \\
\hline & Spirituality, religion and personal beliefs & 6 \\
\hline & Thinking and concentration & 7 \\
\hline & Body image and appearance & 11 \\
\hline & Self-esteem & 19 \\
\hline & Negative feelings & 26 \\
\hline \multirow{3}{*}{ Social } & Relationships & 20 \\
\hline & Sexual activity & 21 \\
\hline & Social support & 22 \\
\hline \multirow{8}{*}{ Environment } & Safety and security & 8 \\
\hline & Physical environment quality & 9 \\
\hline & Finances & 12 \\
\hline & Information access & 13 \\
\hline & Leisure activities & 14 \\
\hline & Home environment & 23 \\
\hline & Access and quality of health care services & 24 \\
\hline & Transport & 25 \\
\hline
\end{tabular}

Note. Adapted from Krägeloh, Henning ${ }^{25}$

The data collection took place over a period of six months and at two different sites: In May of 2014, six regional participants from a wheelchair tennis program run by a university in the south of Brazil were contacted to schedule an appointment for data collection before the beginning of a practice. In October of 2014, 25 participants from an international tournament of wheelchair tennis in the south of Brazil were contacted on the first day of competition to participate in this study; questionnaires were distributed between the athletes' matches, in order not to compromise their participation in the competition.

\section{Data Analysis}

In order to analyze participants' responses provided through the WHOQOL-Bref instrument, the authors performed the data interpretation suggested by the World Health Organization ${ }^{27}$. Specifically for the first question of the questionnaire "How would you rate your QoL?", participants who answered "very poor" " "poor" or "neither poor nor good" were classified with a negative perception, and participants who answered "good" or "very good" were classified with a positive perception. 
Regarding statistical data analysis, descriptive statistics with mean values, standard deviation, and absolute and relative frequency were used (e.g., average years practicing wheelchair tennis). The Shapiro-Wilk test was used to verify the data normality of the quantitative variables. The WHOQOL-Bref domains presenting normal distribution were physical, environment, and the overall score for QoL, whereas the psychological and social domains did not show normal distribution.

Fisher's exact test was performed for the categorically classified variables (QoL perception). Participants' data contained no gender differences. Student's t-test was used to compare the scores of the physical and the environment domains, and the overall QoL between the competitive and elite groups, while the Mann-Whitney U test was performed to compare the scores of psychological and social domains. The effect size was calculated from the information suggested by Cohen $^{28}$. Data were analyzed using SPSS v.21.0. with confidence levels set at $95 \%$.

\section{Results}

By analyzing the general perception of QoL among all participants, this study found that 29 out of the 31 athletes perceived their QoL positively. When observing each group's overall QoL perception, all of the participants of the elite group felt satisfied, whereas two out of the 25 participants of the competitive group presented negative perceptions of QoL. After applying the Fisher's exact test to verify similarities between the two groups, no significant differences were found regarding their general perception of QoL ( $p=.645)$ (See Table 3).

Statistically higher scores were found in the elite group regarding the physical domain $(p=.003)$ and the total score of QoL $(p=.001)$, whereas no statistical differences were found regarding the psychological $(p=.105)$, social $(p=.095)$, and environment domains $(p=.323)$. In addition, the effect size indicated a moderate difference between the groups analyzed for the physical domain and the total score of QoL perception (See Table 4).

Table 3. Quality of life perception according to the competitive level

\begin{tabular}{llll}
\hline & Groups & \multicolumn{2}{c}{ Quality of life perception } \\
\cline { 2 - 3 } & & Positive & Negative \\
\cline { 2 - 3 } & $\mathbf{n}(\%)$ & n (\%) & $2(8.0)$ \\
\hline Elite & $23(92.0)$ & $0(0.0)$ & 0.645 \\
\hline Total & $6(100.0)$ & $2(6.5)$ \\
\hline
\end{tabular}

${ }^{\text {a} F i s h e r ' s ~ e x a c t ~ t e s t . ~}$

Table 4. WHOQOL-Bref's quality of life domains according to the competitive level

\begin{tabular}{lcccccc}
\hline \multicolumn{1}{c}{ Quality of life domains } & Competitive Group & Elite Group & & & \\
& M \pm SD & M \pm SD & p & Cohen'D & Effect Size \\
\hline Physical & $69.4 \pm 13.4$ & $82.1 \pm 6.4$ & $0.003^{\mathrm{b}}$ & 1.209 & 0.517 \\
\hline Psychological & $78.8 \pm 11.7$ & $86.8 \pm 4.9$ & $0.105^{\dagger}$ & 0.891 & 0.407 \\
\hline Social & $77.3 \pm 14.1$ & $87.5 \pm 7.0$ & $0.095^{\dagger}$ & 0.916 & 0.416 \\
\hline Environment & $70.1 \pm 13.8$ & $75.5 \pm 10.7$ & $0.323^{\mathrm{b}}$ & 0.437 & 0.213 \\
\hline Total & $73.9 \pm 10.2$ & $83.0 \pm 3.1$ & $0.001^{\mathrm{b}}$ & 1.207 & 0.516 \\
\hline
\end{tabular}

bStudent’s t-test. †Mann-Whitney U test.

\section{Discussion}

The perceived QoL of athletes with disabilities have been studied in the field of adapted physical activity for many years. Overall, results reveal the positive impact of adapted sports in the QoL perception of these athletes ${ }^{10,12,29}$. However, the research-base is underdeveloped on the QoL of elite athletes with disabilities who participate in the high-performance setting. The current study covered $100 \%$ of the Brazilian national wheelchair tennis team and collected data during one of the biggest wheelchair tennis events in Brazil. Despite the small sample size, the exclusion of players who practice wheelchair tennis recreationally, and those who participate in different competitions around the country, this study's findings magnify the need for heighten their awareness. Faculty and administrators should be developing and implementing strategies to further promote adapted sports in high-performance 
environments, due to the higher scores of QoL among Brazilian elite athletes in comparison to competitive athletes with disabilities.

The first purpose of this study was to identify Brazilian wheelchair tennis athletes' QoL in competitive settings. Although this study focused on wheelchair tennis athletes, our,findings are in agreement with previous research on other adapted sports ${ }^{10,12,14}$. In this particular study, wheelchair tennis might have served as an outlet for these athletes to present a positive QoL, considering that this population often encounters social, physical and psychological barriers throughout their life due to the physical impairments ${ }^{8,30}$. Professionals have demonstrated that when someone has a positive QoL their overall perception of life satisfaction is higher ${ }^{12}$ and consequently, the individual may perceive he/she has better control of his/her life, and may pursue social relationships and engage in activities for personal improvements or for society in general. Most of the data collection process for the current study took place in a competitive environment, which might have influenced negatively the QoL perceptions of both groups due to stress and anxiety. Nevertheless, the results showed that the vast majority of the athletes who participated in this study, regardless of their level of competition, perceived their QoL positively.

The second purpose of this study was to compare QoL domain scores between Brazilian competitive and elite wheelchair tennis athletes. In this respect, the results showed statistically higher scores of the physical domain and the total score of QoL perception in the elite group $(p \leq .05)$. These findings are similar to those reported by Yazicioglu, Yavuz ${ }^{12}$, in which significantly higher scores were found in the physical, psychological, and social domains of QoL in elite adapted sports athletes in comparison to non-sports participants. However, this study highlights the fact that even when comparing two groups of people with disabilities who practice adapted sports, each for a considerable length of time (7.8 years in average), higher levels of competition present higher perceptions of QoL. These findings contradict the existing trend that high-performance sports settings might not be a desirable environment for people with or without disabilities to participate in, given the elevated psychological and physical demands of this context ${ }^{18-20}$. Since our findings suggest that athletes perceive QoL even more positively in a high-performance setting, this information can be used to educate athletes with disabilities and family members who may have reservations about adapted sports in a highly competitive environment, as well as to motivate competitive and elite South American wheelchair tennis athletes to participate in the high-performance context.

In a similar comparative study, Noce, Simim ${ }^{11}$ study also used the WHOQOL- Bref instrument to assess QoL perceptions among ten inactive individuals with disabilities and ten active individuals with disabilities playing wheelchair basketball in Brazil. The authors found total QoL score means of 53.23 for the inactive group and 71.60 for the active group. Moreover, when comparing the scores found by Noce, Simim ${ }^{11}$ to the ones found in this study, some points are important to highlight: a) the elite group of this study presented the highest mean of QoL among these groups (83.0); b) the competitive group of this study and the active group of Noce, Simim ${ }^{11}$ study presented similar means of total QoL (73.9 and 71.6, respectively); c) the inactive group of Noce, Simim ${ }^{11}$ study presented the lowest mean of total QoL (53.2). Therefore, besides adapted sports practice itself, three other important aspects are suggested to promote better
QoL perceptions among athletes with disabilities: a higher per week frequency ${ }^{14}$, the number of years spent participating in adapted sports since the onset of the disability ${ }^{31}$, and this study's suggestion that participation in higher competitive levels also contributes to higher QoL perceptions.

As previously mentioned, QoL is a multidimensional concept that includes the domains of physical, psychological, social, environment, amongst others. Professionals in the field of disability sports have suggested that sports serve as a tool for social integration, to overcome physical and psychological barriers perceived through disabilities, and to promote health and $\mathrm{QoL}^{8,30}$. Although the findings of this study support participation in highperformance adapted sports as an option for promoting a positive QoL for athletes with disabilities, participation in other contexts (e.g., recreational sports) can also bring desired improvements in QoL for this population, considering that the competitive group also presented positive perceptions of QoL (23 out of 25 athletes). According to Zabriskie, Lundberg ${ }^{13}$, participating in other contexts, such as recreational sports, results in better social interactions for individuals with disabilities, as well as helping them to strengthen their quality of family life. These athletes begin to perceive their achievements in adapted sports as something that can affect the family unit positively, which in turn, provides benefits to their families through sports practice and increased self-esteem ${ }^{13}$.

Future research should analyze more deeply the specific factors in the physical domain that provide a higher perception of QoL among professional athletes. Moreover, research is needed to better understand the specific factors that make elite athletes present higher perceived scores of QoL when compared to recreational and competitive players, which were not analyzed in this study, such as: gender, training time (in hours and years), and degree of injury, among others.

\section{Conclusions}

In conclusion, the authors suggest that wheelchair tennis players from Brazil who participated in this study exhibited a positive QoL perception regardless of the level of competition. In addition, the current findings provide evidence that elite wheelchair tennis athletes in Brazil presented a significantly higher overall QoL perception score in comparison to competitive players, namely in the physical domain. However, people with disabilities participating in adapted sports activities do not necessarily need to have the elite competitive level as their ultimate goal; involvement in adapted sports by itself is sufficient for presenting a positive perception of quality of life.

\section{References}

1. Mizen LA, Macfie ML, Findlay L, Cooper S-A, Melville CA. Clinical guidelines contribute to the health inequities experienced by individuals with intellectual disabilities. Implement Sci. 2012;7(1):1.

2. Richardson EV, Smith B, Papathomas A. Disability and the gym: experiences, barriers and facilitators of gym use for individuals with physical disabilities. Disabil Rehabil. 2016;14:1-8. 
3. Koo K-M, Kim C-J, Park C-H, Byeun J-K, Seo G-W. Restrictions of physical activity participation in older adults with disability: employing keyword network analysis. J Exerc Rehabil. 2016;12(4):373-8.

4. JaarsmaEA, Dijkstra PU, Geertzen JHB, Dekker R. Barriers to and facilitators of sports participation for people with physical disabilities: A systematic review. Scand J Med Sci Sports. 2014;24(6):871-81.

5. Malone LA, Barfield J, Brasher JD. Perceived benefits and barriers to exercise among persons with physical disabilities or chronic health conditions within action or maintenance stages of exercise. Disabil Health J. 2012;5(4):254-60.

6. Marck CH, Hadgkiss EJ, Weiland TJ, Van der Meer DM, Pereira NG, Jelinek GA. Physical activity and associated levels of disability and quality of life in people with multiple sclerosis: a large international survey. BMC Neurol. 2014;14(143):1-11.

7. Martin JJ. Benefits and barriers to physical activity for individuals with disabilities: a social-relational model of disability perspective. Disabil Rehabil. 2013;35(24):2030-7.

8. Blauwet C, Willick SE. The Paralympic Movement: using sports to promote health, disability rights, and social integration for athletes with disabilities. PM R. 2012;4(11):851-6.

9. Wilhite B, Shank J. In praise of sport: promoting sport participation as a mechanism of health among persons with a disability. Disabil Health J. 2009;2(3):116-27.

10. Anneken V, Hanssen-Doose A, Hirschfeld S, Scheuer T, Thietje R. Influence of physical exercise on quality of life in individuals with spinal cord injury. Spinal Cord. 2010;48(5):393-9.

11. Noce F, Simim MAM, Mello MT. A percepção de qualidade de vida de pessoas portadoras de deficiência física pode ser influenciada pela prática de atividade física? [Can the Self-Perceived Quality of Life of People with Special Needs be Influenced by Practice of Physical Activity?]. Rev Bras Med Esporte. 2009;15(3):174-8.

12. Yazicioglu K, Yavuz F, Goktepe AS, Tan AK. Influence of adapted sports on quality of life and life satisfaction in sport participants and non-sport participants with physical disabilities. Disabil Health J. 2012;5(4):249-53.

13. Zabriskie RB, Lundberg NR, Groff DG. Quality of life and identity: The benefits of a community-based therapeutic recreation and adaptive sports program. Ther Recreation J. 2005;39(3):176-91.

14. Chatzilelecas E, Filipovic B, Petrinovic L. Differences in quality of life according to the level of physical activity between two groups of basketball players in the wheelchairs. SportLogia. 2015;11(1):11-7.

15. Purdue DEJ, Howe PD. See the sport, not the disability: exploring the Paralympic paradox. Qual Res Sport, Exerc Health. 2012;4(2):189-205.

16. Hassan D, Dowling S, McConkey R, Menke S. The inclusion of people with intellectual disabilities in team sports: Lessons from the youth unified sports programme of Special Olympics. Sport Society. 2012;15(9):1275-90.

17. Davis RW. Teaching disability sport: A guide for physical educators. 2nd ed. Champaign, IL: Human Kinetics; 2010.

18. Gustafsson H, Hassmén P, Kenttä G, Johansson M. A qualitative analysis of burnout in elite Swedish athletes. Psychol Sport Exerc. 2008;9(6):800-16.

19. Theberge N. "Just a Normal Bad Part of What I Do": Elite Athletes' Accounts of the Relationship Between Health and Sport. Sociol Sport J. 2008;25(2):206-22.

20. Waddington I. Sport, health and drugs: A critical sociological perspective. London, UK: Taylor \& Francis, 2000.
21. Columna L, Fernández-Vivo M, Lieberman L, Arndt K. Recreational patterns among Guatemalan families with children with visual impairments. J Phys Act Health. 2015;12(8):1119-27.

22. Perkins K, Columna L, Lieberman L, Bailey J. Parents perceptions of barriers and solutions for their children with visual impairments toward physical activity. J Vis Impair Blind. 2013;107(2):131-42.

23. Roux CJ. Socialization of elite wheelchair tennis players in South Africa. Afr J Phys Health Educ Recreat Dance. 2012;18(4):929-38.

24. Fleck MP, Louzada S, Xavier M, Chachamovich E, Vieira G, Santos $\mathrm{L}$, et al. Aplicação da versão em português do instrumento abreviado de avaliação da qualidade de vida "WHOQOL-bref" [Application of the Portuguese version of the abbreviated instrument of quality life WHOQOL-bref]. Rev Saúde Públ. 2000;34(2):178-83.

25. Krägeloh C, Henning M, Hawken S, Zhao Y, Shepherd D, Billington R. Validation of the WHOQOL-BREF quality of life questionnaire for use with medical students. Educ Health. 2011;24(2):545.

26. Armour K, Macdonald D. Research methods in physical education and youth sport. Abigdon: Routledge; 2012.

27. World Health Organization. Whoqol user manual: Programme on mental health. Geneva, Switzerland:WorldHealth Organization; 1998.

28. Cohen J. Statistical power analysis for the behavioral sciences for the behavioral sciences. 2nded. Hillsdale: Lawrence Erlbaum; 1988.

29. Pereira R, Osborne R, Pereira A, Cabral SI. A importância do desporto de alto rendimento na inclusão social dos cegos: Um estudo centrado no Instituto Benjamin Constant - Brasil. [The importance of high performance sports in social inclusion of blind people: A study centered on Benjamin Constant Institute - Brazil]. Motricidade. 2013;9(2):94-105.

30. Ginis KAM, Jörgensen S, Stapleton J. Exercise and sport for persons with spinal cord injury. PM R. 2012;4(11):894-900.

31. Laferrier JZ, Teodorski E, Cooper RA. Investigation of the Impact of Sports, Exercise, and Recreation Participation on Psychosocial Outcomes in a Population of Veterans with Disabilities: A Crosssectional Study. Am J Phys Med Rehabil. 2015;94(12):1026-34.

\section{Acknowledgements}

We would like to show our gratitude to Professor Robert James Lally for his important insight and expertise that greatly assisted the earlier versions of this manuscript. We also highlight that the network created among the authors was only possible due to the Science without Borders program (programa Ciência sem Fronteiras), funded by CAPES, in which the leading author of this article participated.

\section{Corresponding author}

Vitor Ciampolini, Masters Student

Postgraduate Program in Physical Education, Universidade Federal de Santa Catarina, Centro de Desportos, Laboratório de Pedagogia do Esporte. R. Eng. Agronômico Andrei Cristian Ferreira s/n, Trindade, Florianópolis, SC, Brasil Email: vciampolini@gmail.com

Manuscripted received on January 11, 2017

Manuscripted accepdet on March 12, 2017

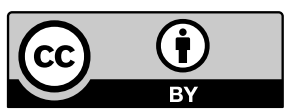

Motriz. The Journal of Physical Education. UNESP. Rio Claro, SP, Brazil - eISSN: 1980-6574 - under a license Creative Commons - Version 3.0 